\title{
Effects of El Nino Southern Oscillation on the Discharge of Kor River in Iran
}

\author{
Morteza Mohsenipour, ${ }^{1}$ Shamsuddin Shahid, ${ }^{1}$ and M. J. Nazemosadat ${ }^{2}$ \\ ${ }^{1}$ Department of Hydraulics \& Hydrology, Faculty of Civil Engineering, Universiti Teknologi Malaysia (UTM), \\ 81310 Johor Bahru, Malaysia \\ ${ }^{2}$ Department of Climate Research Center and Water Engineering, Agriculture Faculty, Shiraz University, Shiraz 71946-84471, Iran
}

Correspondence should be addressed to Shamsuddin Shahid; sshahid@utm.my

Received 6 June 2013; Revised 21 September 2013; Accepted 7 October 2013

Academic Editor: Qi Hu

Copyright (C) 2013 Morteza Mohsenipour et al. This is an open access article distributed under the Creative Commons Attribution License, which permits unrestricted use, distribution, and reproduction in any medium, provided the original work is properly cited.

\begin{abstract}
The objective of the study was to investigate the El Nino forcing on the discharge of Kor River located in Maharloo-Bakhtegan basin in the Fars province of Iran. Thirty-one-year (1965-1995) and twenty-year (1975-1995) monthly mean river discharge data recorded at two stations, namely, Chamriz and Dehkadeh-Sefid, respectively, were chosen in the present study. Fourier analysis was used to extract harmonic information of time series data such as amplitude and phase angle to show the maximum effect and the time of effect of El Nino on river discharge. The study revealed that El Nino events caused increase of discharge in Kor River by $15 \%$ to $20 \%$ and the maximum influence was in the months of February and March in El Nino years.
\end{abstract}

\section{Introduction}

In normal condition, the temperature of ocean surface in the east of southern Pacific Ocean is lower than the temperature of surface water in the west of southern Pacific Ocean. Therefore, a high pressure zone and a low pressure zone dominate in the east and the west of the southern Pacific Ocean, respectively [1]. The difference between high and low pressure zones causes wind blowing, namely, trade wind or easterlies. The direction of wind is from the east to the west of Pacific Ocean. Therefore, trade wind causes the movement of surface warm water in equatorial region from the east to the west. During El Nino period, the temperature of surface water in the west is lower than the temperature of surface water in the east of southern Pacific Ocean. This largescale pressure seesaw in Pacific Ocean is called Southern Oscillation (SO). Therefore, the direction of trade wind and also warm water changes from the west to the east. Existing warm water pool in the coast of Peru and Southern Ecuador is the sign of El Nino $[1,2]$. The two phenomena, El Nino and Southern Oscillation, together are known as ENSO. The relationship between El Nino and some parameters such as temperature, rainfall, and discharge was investigated in different parts of the world. Their results have showed that El Nino causes floods and droughts on different parts around the world [3,4]. Cayan and Peterson [5], Kahya and Dracup [6], Zhang et al. [7], Ward et al. [8], Cahoon [9], Osman and Abdellatif [10], Muñoz-Salinas and Castillo [11], Wang and Eltahir [12], Simpson et al. [13], Kahya, and Karabörk, [14], and many other researchers conducted the impact of El Nino on the discharge. Cayan and Peterson [5] predicted discharge anomalies in the Western United States in two seasons by using Southern Oscillation Index (SOI). Zubair [15] investigated the relationship between ENSO and Mahaweli River discharge in Sri Lanka and showed that El Nino caused declination of river discharge in the months from January to September. Zhang et al. [7] showed that relations between ENSO and yearly maximum discharge in the lower Yangtze River basin were in-phase in China. Chandimala and Zubair [16] presented that the correlation coefficient between ENSO and Kelani River discharge in Sri Lanka was $r=-0.41$. It means that during El Nino events, discharge was lower than normal periods. Ward et al. [8] investigated the sensitivity of river discharge to El Nino Southern Oscillation and concluded that ENSO has a greater 


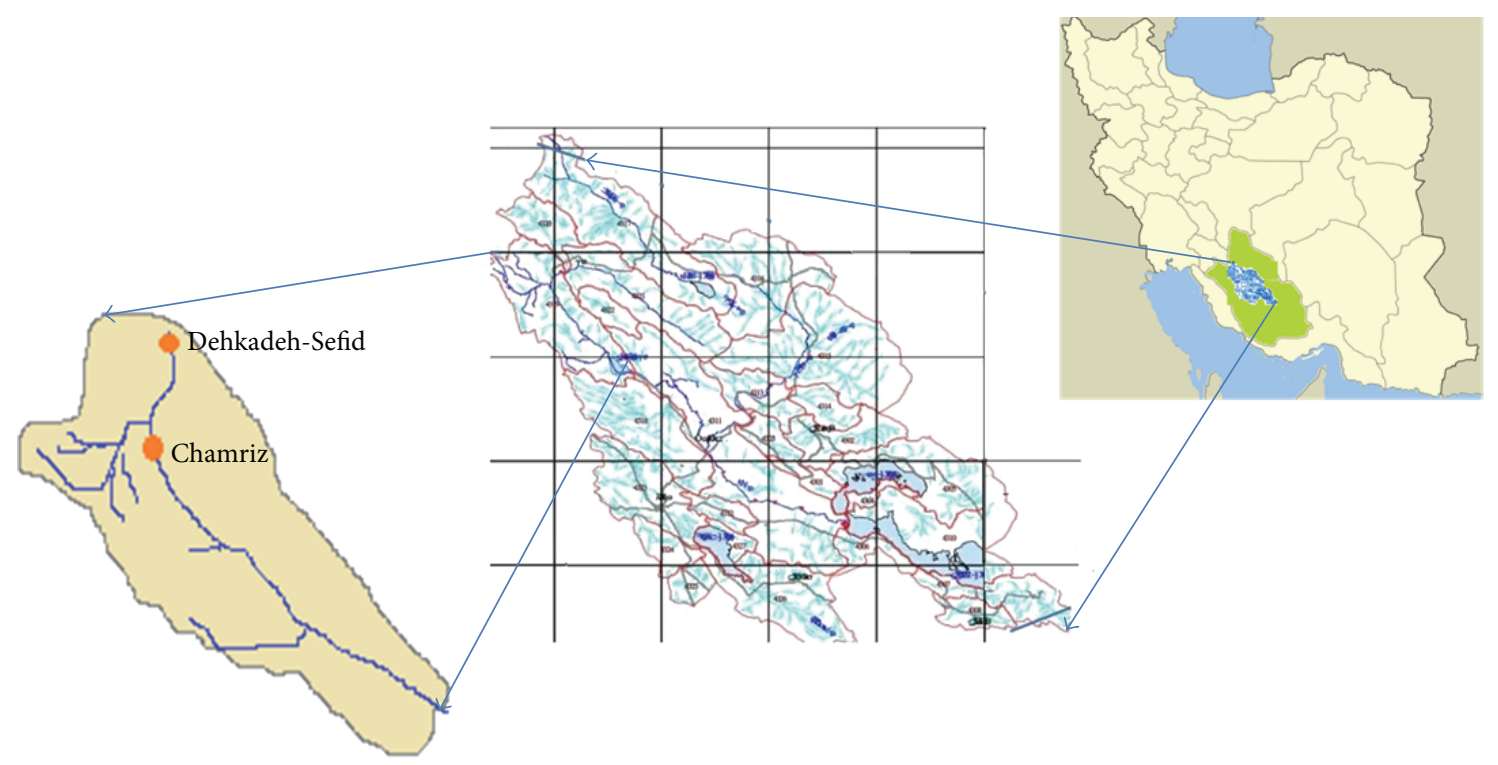

FIGURE 1: Location of two hydrometric stations on Kor River in Maharloo-Bakhtegan basin of Iran.

impact on annual high-flow events than on mean annual discharge, especially in the extratropics. Cahoon [9] studied the effect of ENSO on river flows in the lower Cape Fear River watershed of North Carolina and reported significant effects of ENSO on flows in several winter and spring months. Osman and Abdellatif [10] assessed the links between ENSO and variability of the annual Blue Nile flows and concluded the Blue Nile annual flow index (AFI) is negatively correlated to the ENSO-SST index. Muñoz-Salinas and Castillo [11] assessed the factors controlling sediment and water discharge in the Santiago and Panuco Rivers of central Mexico. Authors reported that water discharge in Santiago River increases during El Nino and La Nina events and the discharge of Panuco River was mostly affected by La Nina events.

Therefore, there is no doubt that El Nino changes precipitation and river discharge which in turn cause floods and droughts and damage to environment and economy [7]. However, the influence of El Nino on rivers discharge is not the same all over the world. A good understanding of El Nino effect on river discharge can help in mitigating hydrological disaster, as well as river basin management and planning. The objective of the present study was to investigate the effect of ENSO on discharge of Kor River located in MaharlooBakhtegan basin in the Fars province of Iran. Thirty-oneyear (1965-1995) monthly mean river discharge data recorded at Chamriz hydrometric station and twenty-one-year (19751995) monthly mean river discharge data at Dehkadeh-Sefid hydrometric station were used in the present study. Harmonic analysis was used to understand the effect of El Nino on river discharge.

\section{Materials and Methods}

2.1. Description of Study Area. Kor River is located in Maharloo-Bakhtegan basin in the Fars province of Iran. Maharloo-Bakhtegan Basin lies between latitudes $28^{\circ} 99^{\prime}-$ $31^{\circ} 25^{\prime} \mathrm{N}$ and longitudes $51^{\circ} 82^{\prime}-54^{\circ} 50^{\prime}$ E. It covers an area of about 31874 million-meter ${ }^{2}$ which is $25 \%$ of the total area of Fars province. Kor River is the most important river in Maharloo-Bakhtegan basin. The location of Kor River, two hydrometric stations, and Maharloo-Bakhtegan basin in Fars province are shown in Figure 1. Stream flow in Kor River is unreliable due to uneven distribution of annual precipitation in the basin. Therefore, Doroodzan Dam was built in Kor River for optimum use of water. The reservoir of dam is around 960 million-meter ${ }^{3}$ which is used for the production of 50 million KWh/year electric energy as well as to supply water for farms covering 112000 hectares in Ramjerd, Kamfiroz, and Korbal regions, industries like petrochemical and drinking water to 2.2 million population in the capital of Fare province, Shiraz, and some areas. Therefore, Kor River plays an important role in agro-economy and people's livelihood in the basin.

Number of research has been conducted on various aspects of Kor River [17-21]. Keshavarzi and Nabavi [17] used stream flow data to predict the frequency of dominant discharge for flood plain management in Kor River. Dolatabadi et al. [20] analysed the stream flow data to identify the percentage of groundwater contribution to stream flow in Maharloo-Bakhtegan Basin which contains the Kor River. Razmkhah [19] employed flood frequency analysis method for flood forecasting in Kor River. Jedari et al. [18] assessed the chemical quality of water of Kor River. Khalifeh et al. [21] used Entropy theory to assess the number and location of hydrometric stations necessary for monitoring hydrodynamics of Maharloo-Bakhtegan Basin. The above studies justify the importance of Kor River in socioeconomy of the region.

2.2. Data Sets. There are 52 hydrometric stations in Kor River basin; however, only 24 hydrometric stations are active. Chamriz and Dehkadeh-Sefid hydrometric stations were selected for two important reasons; first, data in these stations were unimpaired, and second, the duration of data records 


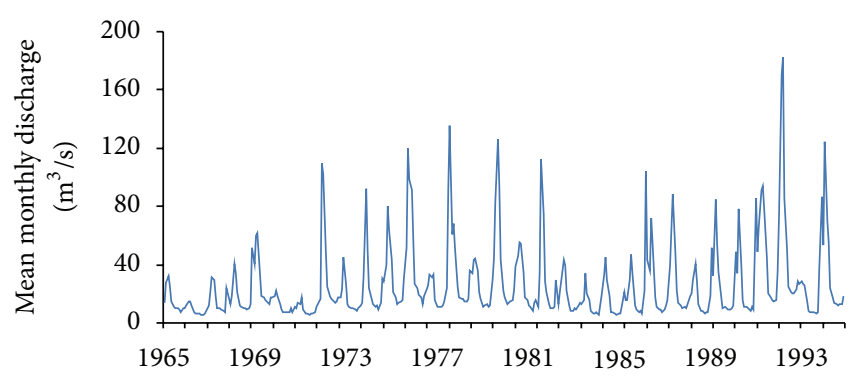

(a)

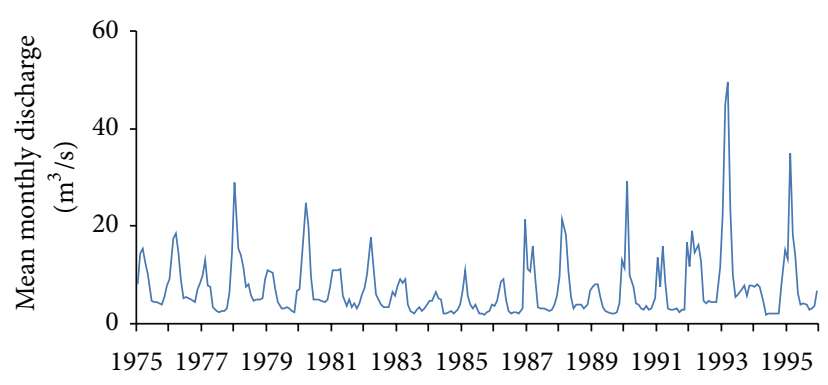

(b)

Figure 2: Time series mean monthly discharge at (a) Chamriz station from 1965 to 1995 and (b) Dehkadeh-Sefid station from 1975 to 1995.

were longer than other stations. Thirty-one-year (1965-1995) monthly mean river discharge data at Chamriz hydrometric station and Twenty-one-year (1975-1995) monthly mean river discharge data at Dehkadeh-sefid hydrometric recorded were used in the present study. As no recent long-term unimpaired river discharge data of Kor River is available, data at those two stations up to 1995 year were used. Data after 1995 was not available and therefore the study analysed data over the time period of 1965-1995 only. However, several number of El Nino events occurred over the time period of 19651995; therefore, it can be expected that analysis of thirty-oneyear data is enough to assess the effects of El Nino Southern Oscillation on the discharge of Kor River.

The river discharge data were collected from the Water Resources Research Center of Iran. Time series of mean monthly discharge at Chamriz and Dehkadeh-Sefid stations are shown in Figures 2(a) and 2(b), respectively. El Nino event years during study period were collected from the Australian Bureau of Meteorology which was derived based on the sea level pressure (Troup's SOI) [22]. According to Troup index if SOI was negative for four consecutive months, it is considered that El Nino event happened in that year. El Nino events during the study period (1965-1995) occurred in the years $1965,1966,1969,1972,1977,1980,1982,1987,1990,1991,1993$, and 1994.

\subsection{Methodology}

2.3.1. Fitting Distribution Function. In the present study, normal, lognormal, Gumbel, and Gamma distributions are fitted over the river discharge data to find the best fitted distribution function. Easy fit professional software which is used for probability analysis was used to find the best fitted distribution function. The general formula for the probability density function of the normal distribution is

$$
f(x)=\frac{1}{\sigma \sqrt{ } 2 \pi} e^{-(x-\mu)^{2} / 2 \sigma^{2}},
$$

where $\mu$ is the location parameter and $\sigma$ is the scale parameter. The mean is the location parameter $\mu$.
Governing equation of the probability density function of lognormal distribution is

$$
f(x)=\frac{1}{x \sigma_{n}(2 \pi)^{0.5}} \exp \left(-\frac{1}{2}\left(\frac{\ln x-\mu_{n}}{\sigma_{n}}\right)\right), \quad x \geq 0,
$$

where $x$ is the raw monthly discharge, the index $n$ in parameters indicates that mean and standard deviations are based on the natural logarithms in the sample, $\mu_{n}$ is the mean of $\ln x$, and $\sigma_{n}$ is the standard deviation of $\ln x$.

The general formula for the probability density function of the Gumbel distribution is

$$
f(x)=\frac{1}{\beta} e^{(x-\mu) / \beta} e^{-e^{(x-\mu) / \beta}},
$$

where $\mu$ is the location parameter and $\beta$ is the scale parameter. The mean is calculated as $\mu+0.5772 \beta$.

The general formula for the probability density function of the Gamma distribution is

$$
f(x)=\frac{((x-\mu) / \beta)^{\gamma-1} \exp (-((x-\mu) / \beta))}{\beta \Gamma(\gamma)}, \quad x \geq \mu, \beta>0,
$$

where $\gamma$ is the shape parameter, $\mu$ is the location parameter, $\beta$ is the scale parameter, and $\Gamma$ is the Gamma function.

2.4. Harmonic Analysis. When periodicity in data does not clearly exist, harmonic analysis is carried out for analysing the periodic components of the data. There are two main ways to calculate the mean curve of a period for harmonic analysis, namely, polynomial regression and Fourier analysis. However, polynomial regression often shows humps in the mean curve when scatter of points is too large. Furthermore, differentiation of such polynomial function can also produce false results [23]. The Fourier series is a sum of sine and cosine functions that describes a periodic signal. It is represented in either the trigonometric form or the exponential form. Fourier analysis provides an easy way to calculate the mean curve of a periodic variable as well as to calculate the times of maxima and minima [24-26]. Number of studies employed Fourier analysis to understand harmonics of hydrological 
data and the effect of large scale atmospheric phenomena on hydrological data. Kahya and Darcup [6] used Fourier analysis to assess the effect of El Nino southern oscillation on the streamflow in major rivers of the United States. Fourier analysis was applied to study the areal and temporal effects on precipitation in the North-Eastern United States by Scotte and Shulman [27]. Therefore, Fourier analysis was chosen in the study to understand the effect of El Nino of Kor River discharge.

Harmonic analysis was carried out to understand the periodic components in stream flow of Kor River as the periodicity was not clearly visible. It appeared that there exists an oscillation in river discharge, but its frequency is unknown. Therefore, Fourier analysis is carried out to estimate the parameters of the oscillation. Fourier analysis revealed the orthogonality property of sinusoids with frequencies restricted to the Fourier frequencies. According to Fourier series, any sine curve can be fitted to the curve of original data. Each fitted sine curve has two features that describe harmonic; the amplitude which indicates the difference between maximum and minimum data, and the phase angle which indicates the time of the year when the maximum happens [27]. Calculation of harmonics by fitting sine curves on data was done by using following equation:

$$
X=\widetilde{X}+\sum_{i=1}^{i=N / 2}\left[A_{i} \sin \left(\frac{360}{p} i t\right)+B_{i} \cos \left(\frac{360}{p} i t\right)\right]
$$

where $X$ represents the discharge at time $t, \widetilde{X}$ is the arithmetic mean of discharge, $p$ is the fundamental period, $N$ is the number of observations, $i$ is the number of the harmonics, $t$ is the phase angle, and $A_{i}$ and $B_{i}$ are the coefficients of Fourier series. Coefficients, $A_{i}$ and $B_{i}$, are the amplitude of the $i$ th harmonic (maximum departure from the mean) and can be written as follows:

$$
\begin{aligned}
& A_{i}=\frac{2}{N} \sum\left[X \sin \left(\frac{360}{p} i t\right)\right], \\
& B_{i}=\frac{2}{N} \sum\left[X \cos \left(\frac{360}{p} i t\right)\right] .
\end{aligned}
$$

Equation (1) can be rewritten as

$$
X=\widetilde{X}+\sum_{i=1}^{i=N / 2} C_{i} \cos \left[\left(\frac{360 i}{p}\left(t-t_{i}\right)\right)\right],
$$

where

$$
\begin{gathered}
C_{i}=\left(A_{i}+B_{i}\right)^{0.5}, \\
t_{i}=\frac{p}{360 i} \arcsin \left(\frac{A_{i}}{C_{i}}\right),
\end{gathered}
$$

where $C_{i}$ is the amplitude of the $i$ th harmonic and $t_{i}$ is the phase angle or the time of maximum influence.

Kahya and Dracup [6] recommended a two-year El Nino composite for calculating duration. Therefore, 24-month period starting from July before El Nino event to June of
TABLE 1: Best fitting distribution function for each month at two stations.

\begin{tabular}{lcc}
\hline \multirow{2}{*}{ Month } & \multicolumn{2}{c}{ Hydrometric station } \\
& Chamriz & Dehkadeh-Sefid \\
\hline January & Lognormal & Lognormal \\
February & Lognormal & Lognormal \\
March & Normal & Lognormal \\
April & Gumbel & Gamma \\
May & Lognormal & Lognormal \\
Jun & Lognormal & Gamma \\
July & Lognormal & Lognormal \\
August & Normal & Lognormal \\
September & Lognormal & Lognormal \\
October & Lognormal & Gumbel \\
November & Gamma & Lognormal \\
December & Lognormal & Lognormal \\
\hline
\end{tabular}

following El Nino event was used in the present study for computation. Minus and plus signs were given for six months before and after the El Nino event, respectively, and zero sign during the El Nino event.

The degree of significance for the amplitude can be written as

$$
\text { Prob }=1-\exp \left[-\left(\frac{C_{i}}{\left(\bar{C}_{p} / \sqrt{N}\right)}\right)^{2}\right]
$$

where

$$
\bar{C}_{p}=\left[\frac{1}{N}\left(\sum_{i=1}^{N} C_{i, p}^{2}\right)\right]^{0.5}
$$

The goodness of fit of the sine curve on time series data was computed by using the following equation:

$$
\text { Goodness of fit }=\frac{C_{i}^{2}}{2 \delta^{2}},
$$

where $\delta$ is the total standard deviation.

\section{Results and Discussion}

3.1. Distribution Function. The best fitted distribution functions in each month at two stations are shown in Table 1. The table shows that the lognormal distribution was domain at Chamriz and Dehkadeh-Sefid hydrometric stations. The best fitted distribution curves on river discharge data for the month of September at Chamriz and Dehkadeh-Sefid stations are shown in Figures 3(a) and 3(b), respectively. High-flow events usually cause positive skew in the frequency distribution of discharge for most of the months. As the logarithmic transformation eliminates the skew, it best fitted the distribution of river discharge in most of the months. As the lognormal distribution was found to best fit the monthly river discharge at about $67 \%$ cases, it was considered to compute parameters for all months to make calculation easy. Therefore, cumulative probabilities for monthly mean discharges were calculated using (2). 


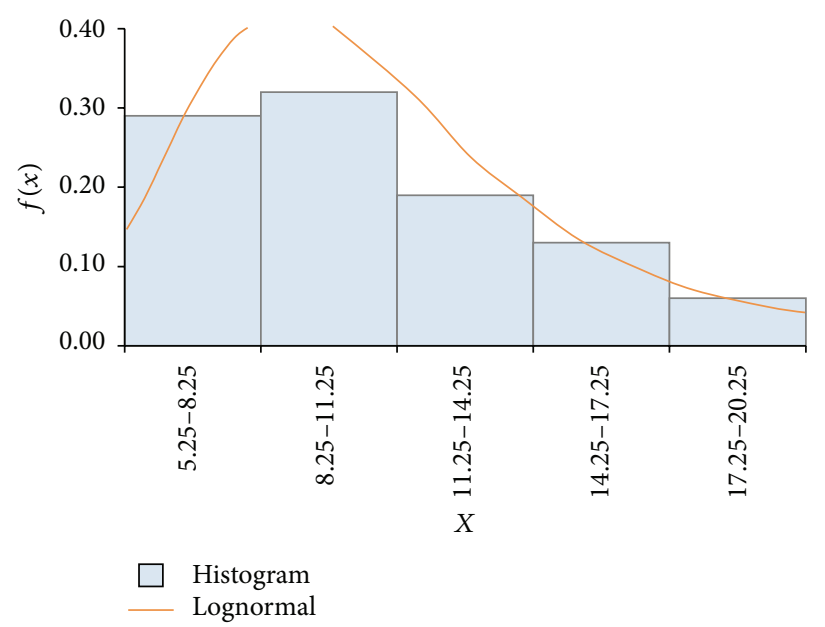

(a)

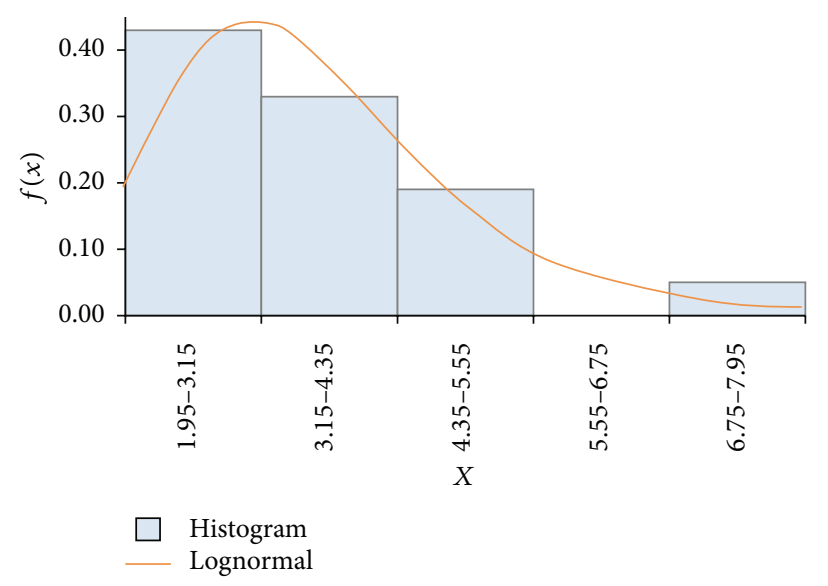

(b)

FIGURE 3: Probability density function at (a) Chamriz station in September and (b) Dehkadeh-Sefid station in September.

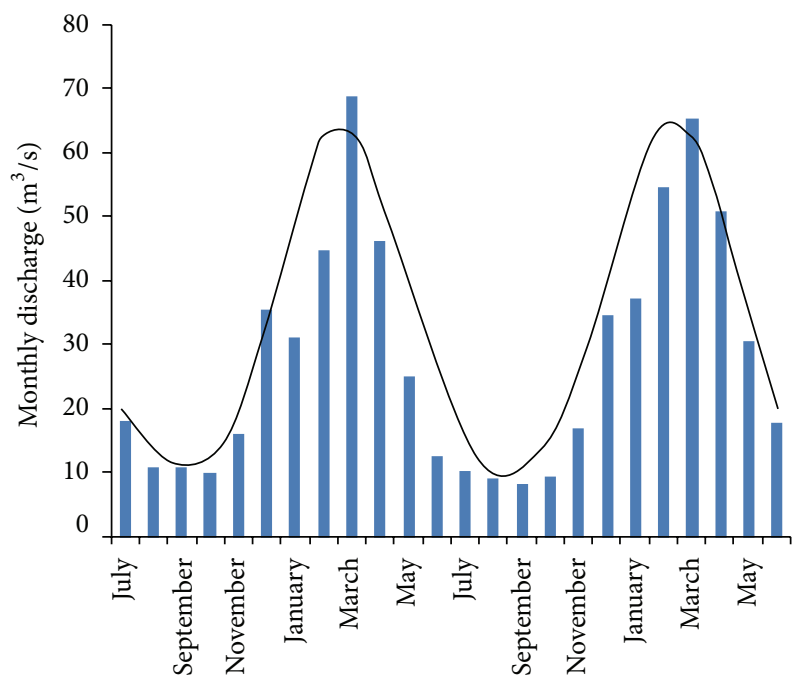

FIGURE 4: Fitted second harmonic on discharge in El Nino event years at Chamriz station.

3.2. Fitting Sine Curve. Harmonics of time series data during El Nino years were fitted with sine curves. First two harmonics of time series data were used to show the influence of El Nino reasonably, because the progress of El Nino events are very slow and happen in large scale [6]. Therefore, the El Nino event years were divided into two groups, namely, the first harmonic domain and the second harmonic domain.

A fitted sine curve on data is shown in Figure 4. The amplitudes of the first and the second harmonics for El Nino event years were calculated using (9). Results showed that calculated amplitudes for the first harmonic were greater than the calculated amplitudes for the second harmonics in $65 \%$ cases at both stations. The mean amplitudes for the first and second harmonics at both stations are shown in Table 2.

The magnitude of the first harmonic represents the magnitude of the streamflow response to the ENSO events
TABLE 2: Calculated parameters of sine curves at two stations under study.

\begin{tabular}{lccc}
\hline & Harmonic & \multicolumn{2}{c}{ Station } \\
& & Chamriz & $\begin{array}{c}\text { Dehkadeh- } \\
\text { Sefid }\end{array}$ \\
\hline \multirow{2}{*}{ Amplitude } & First & 0.1 & 0.12 \\
& Second & 0.14 & 0.10 \\
\hline \multirow{2}{*}{ Mean } & First & 0.55 & 0.58 \\
& Second & 0.51 & 0.50 \\
\hline \multirow{2}{*}{ Influence } & First & $0.1+0.5=0.15$ & $0.12+0.08=$ \\
& & or $15 \%$ & 0.2 or $20 \%$ \\
Goodness of & Fecond & $0.14+0.01=$ & $0.1+0=0.1$ \\
fit (\%) & First & 6.15 or $15 \%$ & or $10 \%$ \\
\hline \multirow{2}{*}{ Significance } & Fecond & 30 & 58 \\
& First & 65 & 35 \\
\hline
\end{tabular}

[6]. A discrepancy occurs in the magnitude of response if the mean and median of a composite are not equal. In that case, Kahya and Dracup [6] proposed that magnitude of the response can be correctly estimated by the summation of the computed amplitude and the difference between the mean and median. For lognormal distribution data, the mean is greater than median. Therefore, the difference between mean and median was added to amplitude to measure the influence. The means of data for the first and the second harmonics at both stations are shown in Table 2. The difference between mean and median were $0.05,0.01$ and $0.08,0$ for the first and the second harmonics at Chamriz and Dehkadeh-Sefid stations, respectively. Therefore the values were added to calculated amplitudes and show the maximum influence of El Nino on discharge. The maximum influences of El Nino on discharges at two stations are shown in Table 2. 


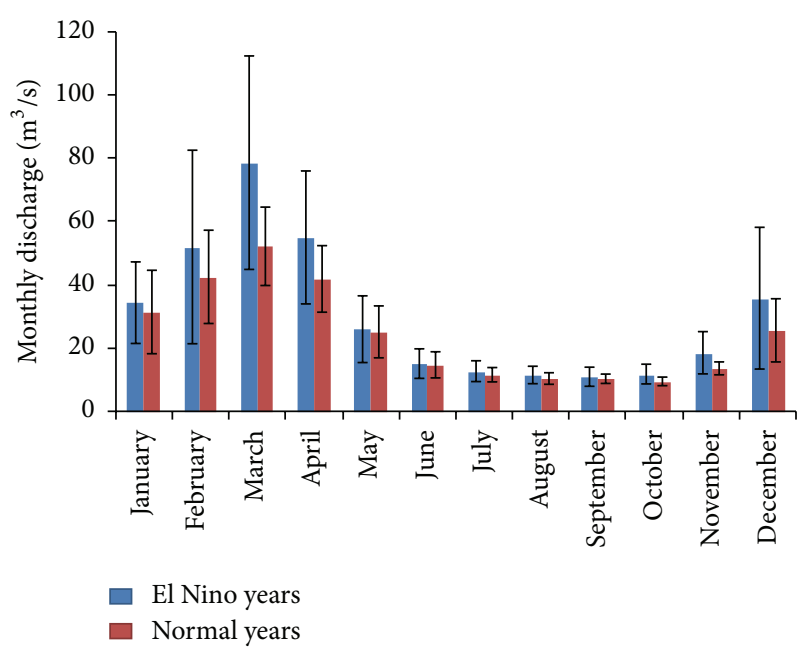

FIgURE 5: Monthly mean discharge during El Nino years and normal years at Chamriz station.

3.3. Goodness Fit and Degree of Significance Test. Equations (13) and (11) were used to calculate the goodness of fit and degree of significance (DOS) of sine curves on data, respectively. The results are shown in Table 2 . It was found that the goodness fit for the first harmonic was much better than the second harmonic. The significant test showed that probability of El Nino effect on discharge amplitudes was high for the first harmonic. The probability was $65 \%$ for Chamriz and $85 \%$ for Dehkadeh-Sefid station.

3.4. Time of Maximum Influence. The phase angle or the time of maximum influence was calculated for the first and the second harmonics using (10). The maximum influence for both stations was found to occur at 7.28th and 8.54th month from the beginning of 24-month period for the first and the second harmonics, respectively. In other words, the maximum influence occurred in the month of February and March of the El Nino year for the first and the second harmonics. The positive sign indicates that El Nino caused increased discharge.

3.5. Comparison of El Nino and Normal Periods. Comparisons between monthly mean discharge in El Nino years and normal years showed good agreement with the obtained results. Figure 5 shows monthly mean discharge and 95\% confidence level of mean discharge for both El Nino years and normal years at Chamriz station. It can be seen from Figure 5 that monthly discharge in the months of March is much higher in El Nino years compared to normal years.

\section{Conclusions}

Fourier analysis was used to extract harmonic information of monthly river discharge data to understand the influence of El Nino on the discharge of Kor River. Amplitude and phase angle, which are two characteristics of Fourier series, were used to show the maximum influence and the time influence of El Nino on river discharge. The results showed that probability of El Nino effect on discharge amplitudes was high for the first harmonic and 65\% and 85\% for Chamriz and Dehkadeh-Sefid stations, respectively. In average, El Nino caused increased discharge by $15 \%$ at Chamriz station and $20 \%$ at Dehkadeh-Sefid station. The time of maximum impact was found in the months of February and March of the El Nino year. It can be expected that the results obtained in the present study will help to understand the variations of river discharge due to El Nino which in turn will help water managers, dam operators, and policy makers in water resources planning and management as well as flood and drought forecasting and mitigation.

\section{References}

[1] S. Vogel, "Deep-root disturbance," Discover, vol. 10, no. 7, pp. 26-29, 1989.

[2] N. Nicholas, "The El Nino-Southern oscillation phenomenon," Report, National Center for Atomic Research, Boulder, Colo, USA, 1987.

[3] S. Jain and U. Lall, "Floods in a changing climate: does the past represent the future?" Water Resources Research, vol. 37, no. 12, pp. 3193-3205, 2001.

[4] P. Aceituno, "On the functioning of the Southern Oscillation in the South American sector. Part I: surface climate," Monthly Weather Review, vol. 116, no. 3, pp. 505-524, 1988.

[5] D. R. Cayan and D. H. Peterson, "The influence of North Pacific atmospheric circulation on streamflow in the west," in Aspects of Climate Variability in the Pacific and the Western of America, D. H. Peterson, Ed., vol. 55 of Geophysical Monograph, pp. 375-397, American Geophysical Union.

[6] E. Kahya and J. A. Dracup, "US streamflow patterns in relation to the El Nino/Southern Oscillation," Water Resources Research, vol. 29, no. 8, pp. 2491-2503, 1993.

[7] Q. Zhang, C.-Y. Xu, T. Jiang, and Y. Wu, "Possible influence of ENSO on annual maximum streamflow of the Yangtze River, China," Journal of Hydrology, vol. 333, no. 2-4, pp. 265-274, 2007.

[8] P. J. Ward, W. Beets, L. M. Bouwer, J. C. J. H. Aerts, and H. Renssen, "Sensitivity of river discharge to ENSO," Geophysical Research Letters, vol. 37, no. 12, Article ID L12402, 2010.

[9] L. Cahoon, "El Niño-Southern oscillation effects on river flows in the lower cape fear River Watershed, North Carolina," Journal of North Carolina Academy of Science, vol. 128, no. 3/4, pp. 7480, 2012.

[10] Y. Z. Osman and M. E. Abdellatif, "El Nino Cycles and variability of the Blue Nile annual flow in the Sudan," in Proceedings of the International Conference on Climate Change Effects, Potsdam, Germany, May 2013.

[11] E. Muñoz-Salinas and M. Castillo, "Sediment and water discharge assessment on santiago and Pánuco rivers (Central Mexico): the importance of topographic and climatic factors," GeografiskaAnnaler A, vol. 95, no. 2, pp. 171-183, 2013.

[12] G. Wang and E. A. B. Eltahir, "Use of ENSO information in medium- and long-range forecasting of the Nile floods," Journal of Climate, vol. 12, no. 6, pp. 1726-1737, 1999.

[13] H. J. Simpson, M. A. Cane, A. L. Herczeg, S. E. Zebiak, and J. H. Simpson, "Annual river discharge in southeastern Australia related to El Nino-Southern Oscillation forecasts of sea surface 
temperatures," Water Resources Research, vol. 29, no. 11, pp. 3671-3680, 1993.

[14] E. Kahya and M. Ç. Karabörk, "The analysis of El Nino and La Nina signals in streamflows of Turkey," International Journal of Climatology, vol. 21, no. 10, pp. 1231-1250, 2001.

[15] L. Zubair, "El Niño-southern oscillation influences on the Mahaweli streamflow in Sri Lanka," International Journal of Climatology, vol. 23, no. 1, pp. 91-102, 2003.

[16] J. Chandimala and L. Zubair, "Predictability of stream flow and rainfall based on ENSO for water resources management in Sri Lanka," Journal of Hydrology, vol. 335, no. 3-4, pp. 303-312, 2007.

[17] A. R. Keshavarzi and S. H. Nabavi, "Dominant discharge in the kor river, fars province, Iran," in Proceedings of the 10th International Water Technology Conference (IWTC '10), pp. 299306, Assiut University, Alexandria, Egypt, 2006.

[18] J. Jedari, E. Moghimi, M. Yamani, H. Mohammadi, and A. R. Eisai, "Effect of eco-geomorphologic on water chemical quality: case study kor river, Iran," Journal Geographic and Environmental Management, vol. 37, no. 1, pp. 17-32, 2009.

[19] H. Razmkhah, "Predict the discharge of flood using frequency analysis: case study, kor river, Iran," in Proceedings of the 1st National Conference on Snow and Avalanche, Iran, 2010.

[20] N. Dolatabadi, A. Farid Hosseni, K. Davari, and A. Mosaedi, "Predict base flow using recursive digital filter: case study maharloo-bakhtegan basin, Iran," in Proceedings of the 3rd International Conference on Integrated Water Management, Iran, 2011.

[21] S. Khalifeh, S. Karimi Goghari, B. Bakhteyari, and E. Khalifeh, "Effect of data categorization on data index to evaluation of hydrometric network," in Proceedings of the 11th National Conference on Irrigation and Evaporation, Iran, 2011.

[22] A. J. Troup, “The Southern oscillation,” Quarterly Journal of Royal Meteorological Society, vol. 91, no. 390, pp. 490-506, 1965.

[23] D. S. G. Pollock, "Investigating economic trends and cycles," in Palgrave Handbook of Econometrics, T. C. Mills and K. Patterson, Eds., vol. 2 of Applied Econometrics, Palgrave Macmillan Ltd, Houndmills, UK, 2008.

[24] B.-Y. Qing, Z.-S. Teng, Y.-P. Gao, and H. Wen, "Approach for electrical harmonic analysis based on nuttall window doublespectrum-line interpolation FFT," Proceedings of the Chinese Society of Electrical Engineering, vol. 28, no. 25, pp. 153-158, 2008.

[25] B. Zeng, Z.-S. Teng, H. Wen, and B.-Y. Qing, "Approach for harmonic analysis based on Rife-Vincent window interpolation FFT,' Proceedings of the Chinese Society of Electrical Engineering, vol. 29, no. 10, pp. 115-120, 2009.

[26] H. Wen, Z. Teng, Y. Wang, and B. Zeng, "Accurate algorithm for harmonic analysis based on minimize sidelobe window," in Proceedings of the International Conference on Measuring Technology and Mechatronics Automation (ICMTMA '10), pp. 386-389, March 2010.

[27] C. M. Scott and M. D. Shulman, "An areal and temporal analysis of precipitation in the northwestern United States," Journal of Applied Meteorology, vol. 18, no. 5, pp. 627-633, 1979. 

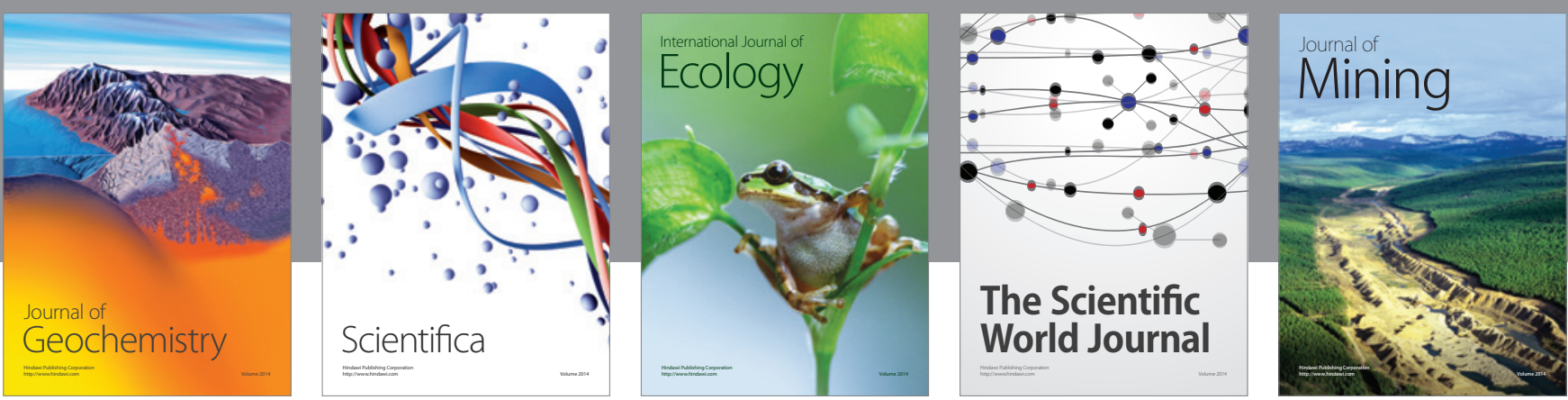

The Scientific World Journal
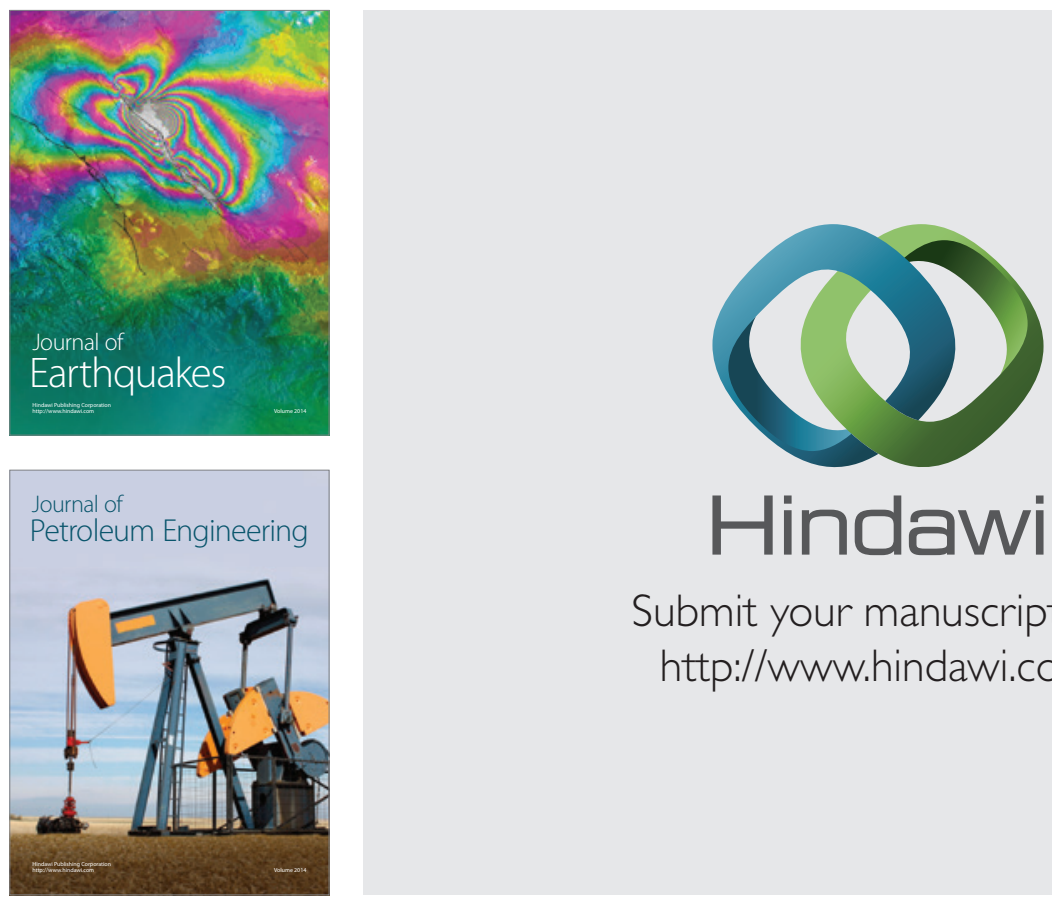

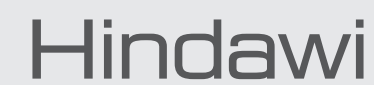

Submit your manuscripts at

http://www.hindawi.com
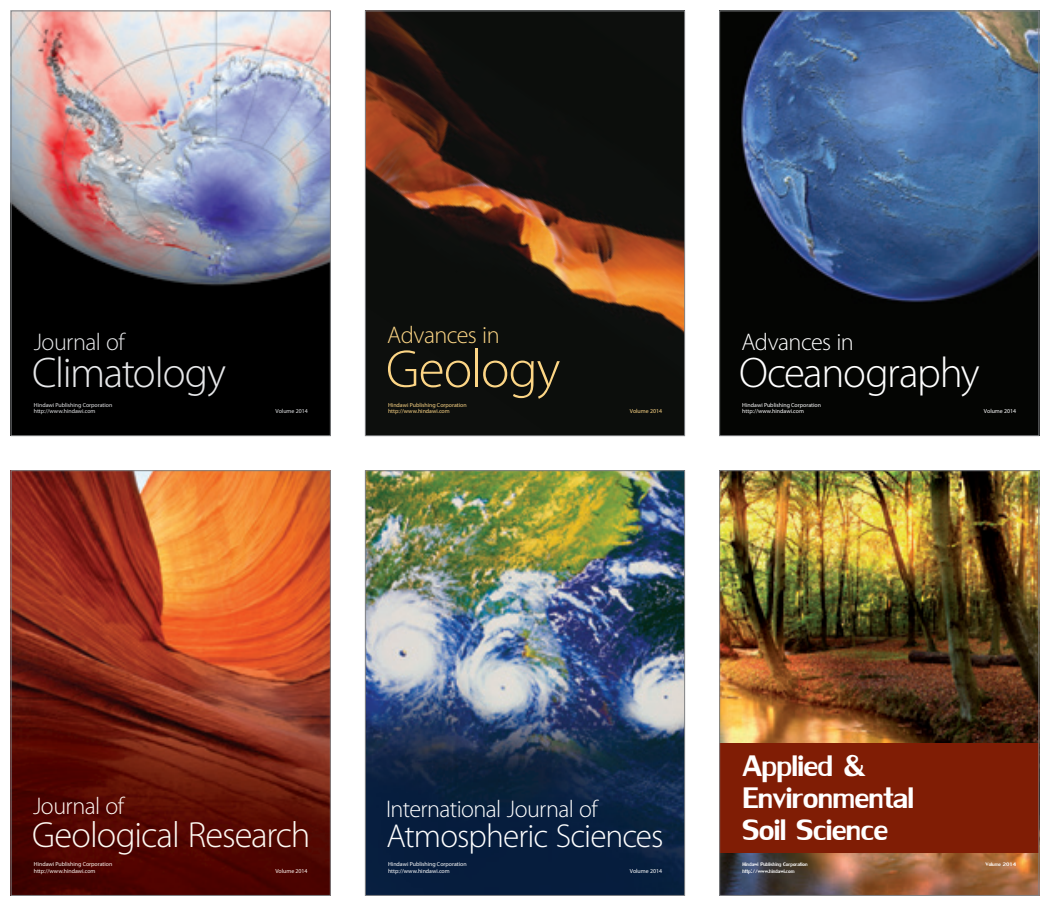
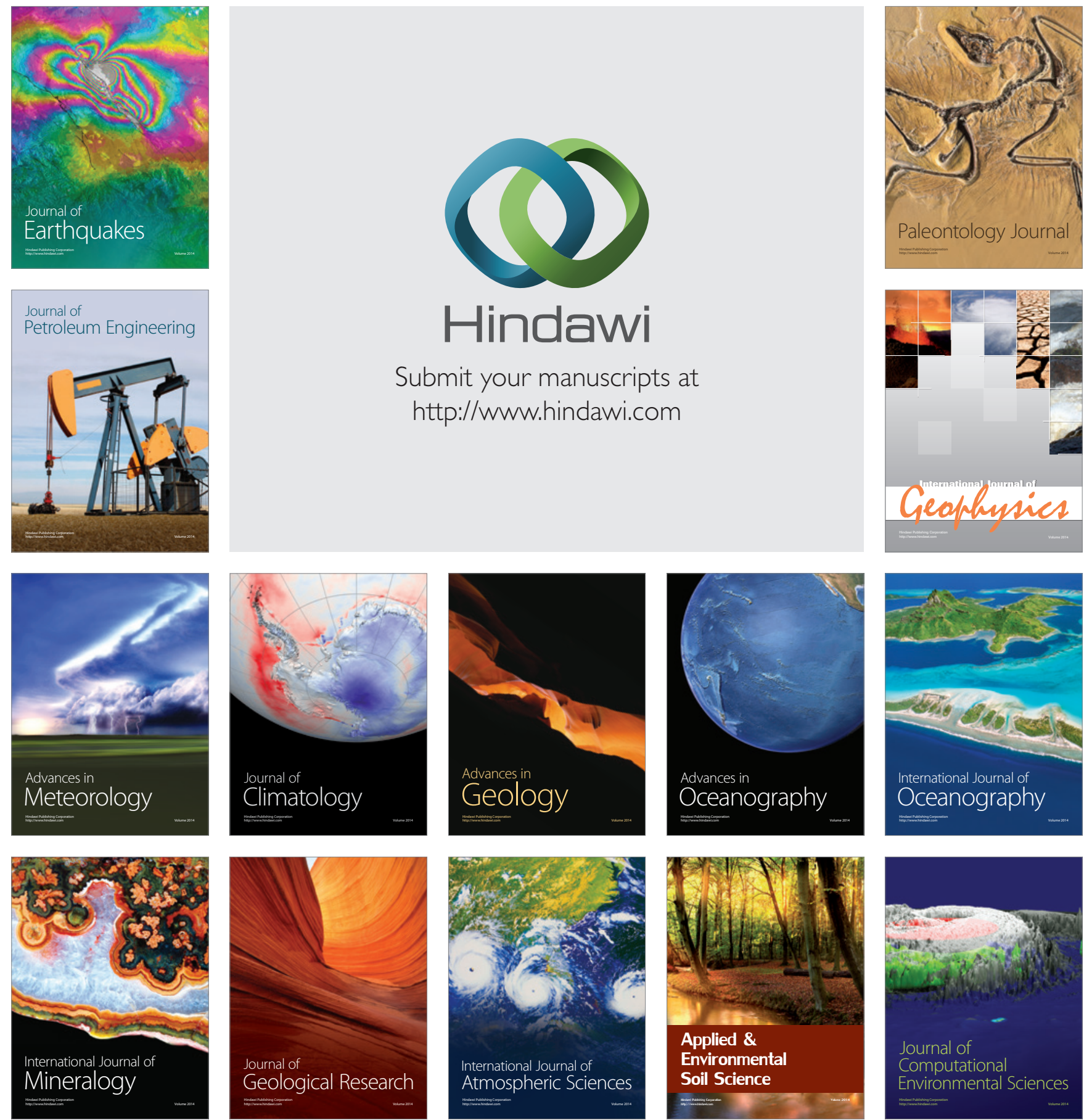